\title{
O Efeito de um Programa de Equoterapia no Desenvolvimento Psicomotor de Crianças com Indicativos de Transtorno de Déficit de Atençáo e Hiperatividade
}

\author{
The Effect of a Horseback Riding Therapy Program on Psychomotor Development of \\ CHILDREN WITH INDICATORS OF ATtENTION DEFICIT HyPERACTIVITY DISORDER
}

\author{
Gardenia de Oliveira BARBOSA ${ }^{1}$ \\ Mey de Abreu van MUNSTER ${ }^{2}$
}

\begin{abstract}
RESUMO: o objetivo do presente estudo foi verificar o efeito de um programa de equoterapia sobre o desenvolvimento psicomotor de crianças com indicativos de transtorno de déficit de atenção e hiperatividade (TDAH). Com relação ao método, foi desenvolvido um estudo exploratório do tipo manipulaçấo experimental. Participaram do estudo cinco crianças com idade entre sete e 10 anos, com indicativos de TDAH obtidos por meio do SNAP IV. Antes e após o período de intervenção os participantes da pesquisa foram submetidos a uma avaliação baseada na Escala de Desenvolvimento Motor (EDM). A intervençãa foi constituída por um programa de equoterapia caracterizado como educação/reeducação, tendo sido composta por 24 sessóes individuais, com duraçáo de 30 minutos, registradas sistematicamente por meio de filmagens e diário de campo. Por meio da análise dos resultados observou-se que o programa exerceu influência em todas as habilidades motoras estudadas, sendo que aspectos psicomotores mais influenciados pelo programa de equoterapia, de acordo com a escala de desenvolvimento motor (EDM), foram respectivamente: organizaçáo espacial, equilíbrio, motricidade fina e esquema corporal; a menor influência foi verificada nos aspectos motricidade global e organização temporal. Considerando que, no pós-teste, a idade motora geral foi estatisticamente significante, concluise, de forma geral, que o programa de equoterapia influenciou positivamente o desenvolvimento dos aspectos psicomotores das crianças com indicativos de TDAH participantes do estudo.
\end{abstract}

PALAVRAS-CHAVE: Educação Especial. TDAH, Equoterapia. Desenvolvimento Psicomotor.

\begin{abstract}
The aim of this study was to investigate the effect of a horseback riding therapy program on the psychomotor development of children with indicators of Attention Deficit Hyperactivity Disorder. Regarding the method, for this exploratory study an experimental manipulation procedure was developed. The study included five children aged seven to 10 years, with ADHD indicators obtained through the SNAP IV. An evaluation based on the Motor Development Scale (MDS) was carried out with the study participants before and after the intervention period. The intervention consisted of a horseback riding therapy program with education/reeducation aims. Twenty four individual sessions were carried out, lasting 30 minutes each; these sessions were systematically recorded through videotaping and field diary notes. The analysis of the results showed that the horseback riding therapy program affected all motor skills under investigation, and the greatest improvement of psychomotor aspects, according to the motor development scale (MDS) involved, respectively: spatial organization, balance, fine motor skills and body schema; global motor coordination and temporal organization aspects showed less improvement. Since at posttest, overall motor age was statistically significant, it was concluded that, generally speaking, the horseback riding therapy program had a positive influence on the development of psychomotor aspects of children with ADHD involved in the study.
\end{abstract}

KEYWORDS: Special Education. ADHD. Horseback Riding Therapy. Psychomotor Development.

\footnotetext{
${ }^{1}$ Doutoranda do Programa de Pós-Graduação em Educaçâo Especial da Universidade de São Carlos, São Carlos, SP, Brasil. garativ.@gmail.com

${ }^{2}$ Docente- Professor Adjunto IV, Programa de Pós-graduação em Educação Especial, Departamento de Educação Física e Motricidade Humana, Universidade Federal de São Carlos Universidade Federal de São Carlos, São Carlos, SP, Brasil. munster.mey@gmail.com
} 


\section{IntroduÇấo}

Com o avanço da neurofisiologia no século XIX, foi possível evidenciar uma série de disfunçóes no sistema nervoso central (SNC) sem que estivessem relacionadas a lesóes pontuais ou localizadas de forma clara; assim, têm sido evidenciados diferentes distúrbios que não correspondem a uma área anatômica clara do SNC. Devido à necessidade de nomear uma área para designar alguns fenômenos surgiu, em 1870, o termo psicomotricidade (FALCÃO; BARRETO, 2009).

As primeiras concepçôes acerca da psicomotricidade abordam aspectos neurológicos. Henry Wallon (1879-1962), médico, psicólogo e pedagogo, trouxe informaçóes de grande valor científico acerca do desenvolvimento neurológico do recém-nascido e psicomotor da criança, sendo considerado o precursor da psicomotricidade; influenciado pelos estudos de Wallon, em 1935, Edouard Guilman (1901-1983), deu início a prática psicomotora, promovendo a reeducação psicomotora por meio de adequações na atividade tônica, na atividade de relação e controle motor (FALCÁO; BARRETO, 2009).

Em sua obra, Le Boulch (1987) aborda a influência da educação pelo movimento como auxílio às crianças com dificuldades escolares, discorrendo sobre problemas de "psicomotricidade e atenção", explorando inadequaçôes de desatenção diretamente relacionados a alterações de organização da imagem corporal. Wallon, em sua obra "A Criança Turbulenta" de 1925, descreve problemas de comportamento, posteriormente denominados de "instabilidade psicomotora" ou "síndrome hipercinética", onde as crianças eram vistas como turbulentas e insuportáveis, sendo tais características atribuídas ao excesso motor e verbal e, à incapacidade de manter a atenção por tempo prolongado. Tais características comportamentais podiam se manifestar nos primeiros anos escolares e geralmente vinham acompanhadas de atraso escolar (LE BOUCH, 1987).

As observações realizadas por Jean Le Bouch e Wallon, associadas à descrição acerca das crianças agitadas levam a refletir a respeito das similaridades das características apresentadas nos tempos atuais pelas crianças com Transtorno de Déficit de Atenção e Hiperatividade (TDAH).

Desde os anos 70, crianças com TDAH têm sido diagnosticadas com divergências na quantidade e qualidade de movimentos quando comparadas a crianças com desenvolvimento típico, alterações essas que sugeriram descompassos na regulação da atividade motora, para suprir as demandas motoras impostas em diferentes situações (PEREIRA; ARAUJO; MATTOS, 2005).

Tais inadequações comportamentais e motoras são evidenciadas em crianças no ambiente escolar. Antes dos sete anos, a criança já apresenta comportamento diferenciado em outros contextos, porém fica mais evidente quando está no ambiente escolar e suas ações destoam de outras crianças. A maturação neuronal encefálica tem uma progressão pósteroanterior, ou seja, as áreas anteriores mielinizam-se por último; assim neuroevolutivamente é possível identificar comportamentos hiperativos de crianças em torno de quatro a cinco anos, pois a área pré-frontal completa o processo mielinogenético nessa idade (ROHDE; HALPERN, 2004). O TDAH está associado a uma série de consequências, sendo uma delas as alterações motoras que influenciam nas atividades escolares e de vida diária (POETA; ROSA-NETO, 2005). 
A equoterapia por meio do movimento tridimensional proporcionado pelo cavalo ao passo traz uma série de benefícios (STERBA et al., 2002; MEREGILLANO, 2004; GRAUP; OLIVEIRA; LINK, 2006; COPETTI et al., 2007; MURPHY; KAHN-D'ANGELO; GLEASON, 2008; NEGRI; ARRUDA; CUNHA; 2008; FRANK; MCCLOSKEY; DOLE, 2011). Medeiros e Dias (2002) afirmam que pelo alinhamento do centro de gravidade homem/ cavalo é possível acionar o sistema nervoso, alcançando objetivos neuromotores como: melhora do equilíbrio, ajuste tônico, alinhamento corporal, consciência corporal, coordenação motora e força muscular.

Ainda, o deslocamento no movimento tridimensional estimula diversos sistemas sensoriais, proporcionando benefícios psíquicos, melhorando o aprendizado gnósico-visual e auditivo, favorecendo também o equilíbrio e a conscientização corporal do indivíduo com necessidades especiais levando ao estímulo e a aprendizagem de atividades funcionais (MEDEIROS; DIAS, 2002).

Além disso, Freire (2000) aponta que sinergias funcionais podem ser desenvolvidas por meio da equoterapia, observando ainda que padróes de movimentos coordenados de controle podem ser aprendidos devido a necessidade de permanecer com o centro de gravidade alinhado a base de suporte dinâmica gerada pela movimentação do cavalo. Dessa forma, partese da hipótese de que a equoterapia possa contribuir com o desenvolvimento psicomotor das crianças com indicativos de TDAH envolvidas no presente estudo.

A pesquisa teve por objetivo verificar o efeito de um programa de educação/reeducação de equoterapia sobre o desenvolvimento psicomotor de crianças com TDAH.

Assim, foi proposta uma intervenção baseada em um programa de equoterapia, visando promover estímulos e situaçóes motoras diferenciadas, com a utilização do cavalo como instrumento pedagógico. De modo a proporcionar vivências motoras que pudessem contribuir com o desenvolvimento psicomotor ordenado e com isso promover inputs aferentes adequados ao córtex. influenciando assim, todo sistema cortical na tentativa de quando solicitada uma ação motora esta possa se manifestar de forma adequada conforme as demandas do ambiente, e assim subsidiar indiretamente melhores condiçóes para que ocorra o processo de ensino-aprendizagem.

\section{Método}

O presente estudo foi do tipo exploratório caracterizando-se por proporcionar ao pesquisador o desenvolvimento de hipóteses, maior aproximação com a situação de estudo e elucidação de conceitos. Para tanto, utilizou-se de procedimentos sistemáticos para análise de dados ou aquisição de observações empíricas (MARCONI; LAKATOS, 1990). Devido a manipulação de uma variável independente, de modo a verificar o efeito da mesma em variáveis dependentes associadas em ambiente natural, e, por demonstrar a viabilidade de um programa como solução prática caracteriza-se o delineamento do estudo como sendo do tipo manipulação experimental (MARCONI; LAKATOS, 1990). A variável independente do presente estudo foi o programa de equoterapia e as variáveis dependentes foram referentes aos seguintes aspectos psicomotores: motricidade fina, motricidade global, equilíbrio, esquema corporal, organização espaço - temporal e lateralidade. 


\subsection{Participantes}

Participaram do estudo cinco crianças (quatro do sexo masculino e uma do feminino), com idade entre sete e 10 anos, com indicativos de transtorno de déficit de atenção e hiperatividade (TDAH). Os participantes foram provenientes de escolas públicas e particulares, por indicaçáo de psicopedagogas e neurologistas; no quadro 1 pode ser encontrada a caracterização dos participantes.

Quadro 1: Caracterização dos participantes

\begin{tabular}{c|c|c|l|l|l|l|l|l}
\hline Nome & Idade & Gênero & Escola & Atividades & Terapias & $\begin{array}{l}\text { Medica- } \\
\text { mentos }\end{array}$ & $\begin{array}{l}\text { Hiperativida- } \\
\text { de/impulsi- } \\
\text { vidade média } \\
\text { do SNAP-IV }\end{array}$ & Frequência \\
\hline P1 & 8 & M & Pública & $\begin{array}{l}\text { Recreaçáo } \\
\text { na escola } \\
\text { Kumon (por- } \\
\text { tuguês) }\end{array}$ & $\begin{array}{l}\text { Psicóloga } \\
\text { Fonoaudióloga } \\
\text { Psicopedagoga }\end{array}$ & Ritalina & 7 & $100 \%$ \\
\hline P2 & 7 & F & Particular & Teatro & --- & --- & 8,5 & $96 \%$ \\
\hline P3* & 10 & M & Pública & --- & --- & --- & 7 & $100 \%$ \\
\hline P4 & 9 & M & Particular & --- & Psicopedagoga & Ritalina & 7 & $96 \%$ \\
\hline P5 & 7 & M & Particular & Teatro & --- & $\begin{array}{l}\text { Homeo- } \\
\text { pático }\end{array}$ & 8 & $100 \%$ \\
\hline
\end{tabular}

Fonte: Barbosa (2013).

*Diagnóstico de TDAH

Como critérios de inclusão estabeleceu-se: crianças com indicativos de TDAH $\left(\mathrm{SNAP}_{\mathrm{IV}}\right)^{3}$ com faixa etária entre sete e 10 anos. Já como critério de exclusão foi determinada a falta de disponibilidade em participar das sessóes de intervenção como também a presença de deficiências ou doenças associadas aos indicativos de TDAH; e, como critério de descontinuidade foi estabelecido frequência inferior a 75\% (ausência em 6 ou mais sessões) durante o período de intervenção em equoterapia.

\subsection{Ambiente de Pesquisa}

A pesquisa foi desenvolvida no Núcleo de Estudos em Atividade Física Adaptada (NEAFA) - UFSCar e no Centro Hípico Damha. No NEAFA foram realizadas as avaliaçóes com a Escala de Desenvolvimento Motor (EDM) (ROSA NETO, 2002), pré e pós intervenção; o local dispóe de espaço adequado para realização dos testes propostos pela escala. No centro hípico Damha foram desenvolvidas as atividades equoterápicas, pois o ambiente é preparado para essa finalidade. O centro hípico dispóe de infra-estrutura para prática equoterápica como redondel, pistas de grama, areia e terra como também área coberta para desenvolvimento das atividades em condiçóes climáticas que não possibilitem a prática em área externa, como em dias de chuva.

${ }^{3}$ O SNAP IV é um instrumento de domínio público, desenvolvido por Pliska, Carlson e Swanson (2001) para o diagnóstico dos sintomas de TDAH. Foi elaborado a partir da evolução das versóes mais atuais do "Diagnostic and Statistical Manuals of Mental Disorders", desenvolvido nos anos 80 pela Associação Americana de Psiquiatria. O SNAP IV é validado em diversos países, inclusive no Brasil. 


\subsection{Período}

A intervenção foi composta por 24 sessóes de equoterapia com duração de 30 minutos cada, totalizando três meses. A intervenção foi individual, sendo duas vezes semanais em dias alternados (terças e sextas-feiras) em horários contrários às atividades escolares.

\subsection{Coleta dos dados}

Foi utilizada a EDM (ROSA NETO, 2002) que pode ser aplicada em crianças de dois a 11 anos de idade, e é indicada para os seguintes casos: transtornos na coordenação motora; dificuldades na aprendizagem escolar; atrasos no desenvolvimento neuropsicomotor; problemas na fala, na escrita e em cálculo; hiperatividade, ansiedade, falta de motivação; alteraçóes mentais, sensoriais e motoras. Os dados obtidos forneceram informaçóes referentes à: motricidade fina (MF) (óculo manual); motricidade global (MG) (coordenação); equilíbrio (E) (postura estática); esquema corporal (EC) (imitação de postura, rapidez); organização espacial (OE) (percepção do espaço); organização temporal (OT) (linguagem, estruturas temporais) e lateralidade (L) (mãos, olhos e pés).

Também foi utilizado como diário de campo, um protocolo de registro desenvolvido pela pesquisadora para sistematizar a observação; tal instrumento foi desenvolvido com base na experiência em intervenção com equoterapia, visando suprir as necessidades do projeto de pesquisa, de modo que pudesse contemplar o que seria desenvolvido no decorrer do programa e possibilitar o registro sistemático. A filmagem foi utilizada como recurso auxiliar ao registro sistemático das observaçóes descritas no diário de campo, bem como para verificar o envolvimento dos participantes com as atividades propostas na intervenção em equoterapia. Foi necessária a participação de um assistente de pesquisa, o qual ficou responsável por acompanhar e filmar cada uma das sessóes. Por limitação de espaço, a descrição completa e detalhada do programa de intervenção pode ser encontrada em Barbosa (2013).

\subsection{ANÁlISE dos DADOS}

Para tratamento quantitativo dos dados foi utilizado o teste não- paramétrico de Wilcoxon Pareado, com $\mathrm{p} \leq 0,05$ realizado com auxílio do software SPSS 19. O teste de Wilcoxon Pareado é uma modalidade de teste não-paramétrico utilizado para comparar duas amostras relacionadas, pareadas, ou medições repetidas em uma única amostra, empregada para avaliar se as medidas de posição de duas variáveis são iguais. Este teste é usualmente utilizado como uma alternativa para os testes t de Student ou t pareado quando a população não segue distribuição Normal ou quando as amostras em questão são pequenas (o que não nos impede de utilizá-lo em situaçóes onde se tem grandes amostras).

De modo a realizar uma análise mais fidedigna dos dados, associando a análise quantitativa com a qualitativa foi utilizada a análise descritiva do diário de campo.

\subsection{Aspectos ÉTICos}

Com relação aos aspectos éticos, o projeto de pesquisa foi encaminhado ao Comitê de Ética em Pesquisa em Seres Humanos da de acordo com a Resolução nº 196/96 do Conselho 
Nacional de Saúde, e somente após ter sido aprovado pelo Parecer n 434/2011, a pesquisadora entrou em contato com as escolas, psicopedagogas, neurologistas e pais/responsáveis para expor os objetivos da pesquisa, procedimentos e solicitar a permissão para que as crianças pudessem participar do programa de equoterapia que foi oferecido gratuitamente. Os pais que autorizaram a participação da criança assinaram o Termo de Consentimento Livre e Esclarecido (TCLE).

\section{Resultados e Discussão}

É possível observar na figura 1 que, de forma geral, todas as aptidóes motoras analisadas (motricidade fina, motricidade global, equilíbrio, esquema corporal, organização espacial e organização temporal) obtiveram aumento após o programa de intervenção, representadas também pela Idade Motora Geral que é a soma dos resultados positivos das provas motoras em meses.

\begin{tabular}{l|c|c|c|c|c|c}
\hline Variável & $\begin{array}{c}\text { Mediana } \\
\text { pré }\end{array}$ & $\begin{array}{c}\text { Mediana } \\
\text { pós }\end{array}$ & $\begin{array}{c}\text { Média } \\
\text { pré }\end{array}$ & $\begin{array}{c}\text { Média } \\
\text { pós }\end{array}$ & $\begin{array}{c}\text { Diferença entre } \\
\text { as médias }\end{array}$ & P-valor \\
\hline Motricidade Fina (MF) & 84 & 108 & 85,2 & 104,4 & 19,2 & 0,102 \\
\hline Motricidade Global (MG) & 108 & 108 & 103,2 & 105,6 & 2,4 & 0,317 \\
\hline Equilíbrio (E) & 96 & 102 & 91,2 & 100,8 & 9,6 & 0,066 \\
\hline Esquema Corporal (EC) & 84 & 84 & 79,2 & 86,4 & 7,2 & 0,180 \\
\hline Organizaçáo Espacial (OE) & 72 & 108 & 81,6 & 105,6 & 24 & 0,074 \\
\hline Organizaçáo Temporal (OT) & 96 & 96 & 91,2 & 98,4 & 7,2 & 0,317 \\
\hline Idade Motora Geral (IMG) & 90 & 102 & 88,6 & 100,2 & 11,6 & $\mathrm{P}<0,041^{*}$ \\
\hline
\end{tabular}

Figura 1: Tabela com o valor da mediana e média pré e pós intervenção, diferença entre as médias e p-valor das variáveis

Fonte: Barbosa (2013). * * Estatisticamente significante

Na figura 1 é possível observar que houve alteração estatisticamente significante com relação ao ganho na idade motora geral (IMG) $(\mathrm{p}<0,041)$ dos praticantes para $\mathrm{p} \leq 0,05$.

As aptidóes motoras foram trabalhadas no decorrer de todo o programa de equoterapia e por meio da análise dos dados obtidos na figura 1, podemos inferir que o programa de equoterapia de forma geral influenciou positivamente o desenvolvimento e/ou aprimoramento das aptidóes motoras dos praticantes, refletindo de forma estatisticamente significante no ganho quanto à idade motora geral. Podemos inferir ainda, hierarquizando pela diferença entre as médias, que organização espacial $(\mathrm{OE})$, motricidade fina $(\mathrm{MF})$, equilíbrio (E), esquema corporal (EC) e organização temporal (OT), foram às aptidóes mais influenciadas pelo programa de equoterapia e a menos influenciada foi a motricidade global (MG).

Crianças com TDAH necessitam ser amparadas em diferentes contextos, destacando nesse estudo os aspectos psicomotores, pois a equoterapia, devido as passadas repetidas do cavalo, percurso, intensidade, frequência e ritmo promove vivências relativas ao movimento, espaço, tempo e dimensão, sendo, portanto uma atividade rica em estímulos psicomotores, os quais são transmitidos ao praticante (MARINS, 2010). 
O quadro 2 mostra a classificação do quociente motor geral (QMG) e a idade positiva (IP) ou idade negativa (IN) para cada um dos praticantes, o que indica em quantos meses o praticante está acima ou abaixo da idade cronológica antes e após passar pela intervenção caracterizada pelo programa de equoterapia.

Quadro 2 - Classificação do QMG e IP/IN para cada praticante, cavalo vermelho representa QMG pré e o verde o pós

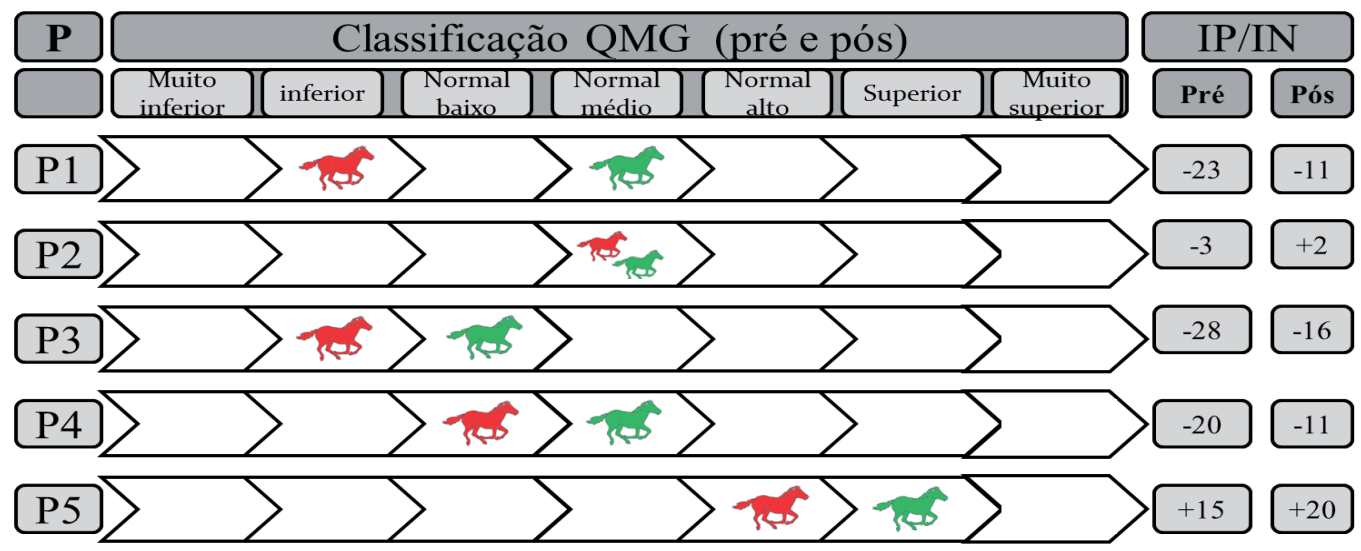

Fonte: Barbosa (2013).

De acordo com o quadro 2 verifica-se que houve melhora na classificação referente ao Quoeficiente Motor Geral dos participantes: P1 avançou 2 níveis; P3, P4 e P5 avançaram 1 nível e P2 manteve-se no mesmo nível, observando melhora em relação à idade; nota-se que após o programa de equoterapia os praticantes tiveram um acréscimo de cinco a 12 meses (média de 8,6 meses) em idade cronológica, isto é, os ganhos proporcionados aproximaram as habilidades motoras adquiridas ao adequado para a idade.

O cavalo, comandado em percursos, proporciona movimentos tridimensionais e multidirecionais possibilitando uma série de informaçóes simultâneas ao corpo humano como transferências do peso corporal, controle bimanual sobre as rédeas, comandos por meio dos pés entre outros; facilitando a estimulação sensorial (visual, tátil, auditiva), coordenação motora global e viso-motora, lateralidade e equilíbrio. Os ganhos anteriormente referidos são influenciados por posicionamento adequado e habitual sobre o cavalo, posicionamento este que se inicia com o praticante sobre o animal parado devido a movimentos de abdução e rotação externa dos membros inferiores e posicionamento dos pés no estribo. As possibilidades de atividades com o auxílio do cavalo são inúmeras, conforme descrito em Barbosa (2013). Com estímulos realizados pelos diferentes tipos de andadura do cavalo, oscilaçóes e movimentos com a finalidade de promover, devido aos estímulos sensoriais, ativação e modulação nervosa capazes de emitir como resposta eferente (motora) um conjunto de ativaçóes sensoriais, adequaçóes e readequaçóes posturais; há, portanto, constante requisição do controle postural e da atenção (MARINS, 2010). 
Os gráficos seguintes pretendem ilustrar o perfil motor individual dos participantes antes e após o programa de equoterapia, de modo a indicar as mudanças positivas e negativas quanto às aptidóes motoras (motricidade fina, motricidade global, equilíbrio, esquema corporal, organização espacial e organizaçáo temporal) e consequentemente na idade motora geral para cada um dos praticantes.

Ao analisar a figura 2, notamos que P1 apresentou melhora em praticamente todas as áreas, exceto por permanecer com as mesmas medidas na motricidade global (MG) e organização temporal (OT).

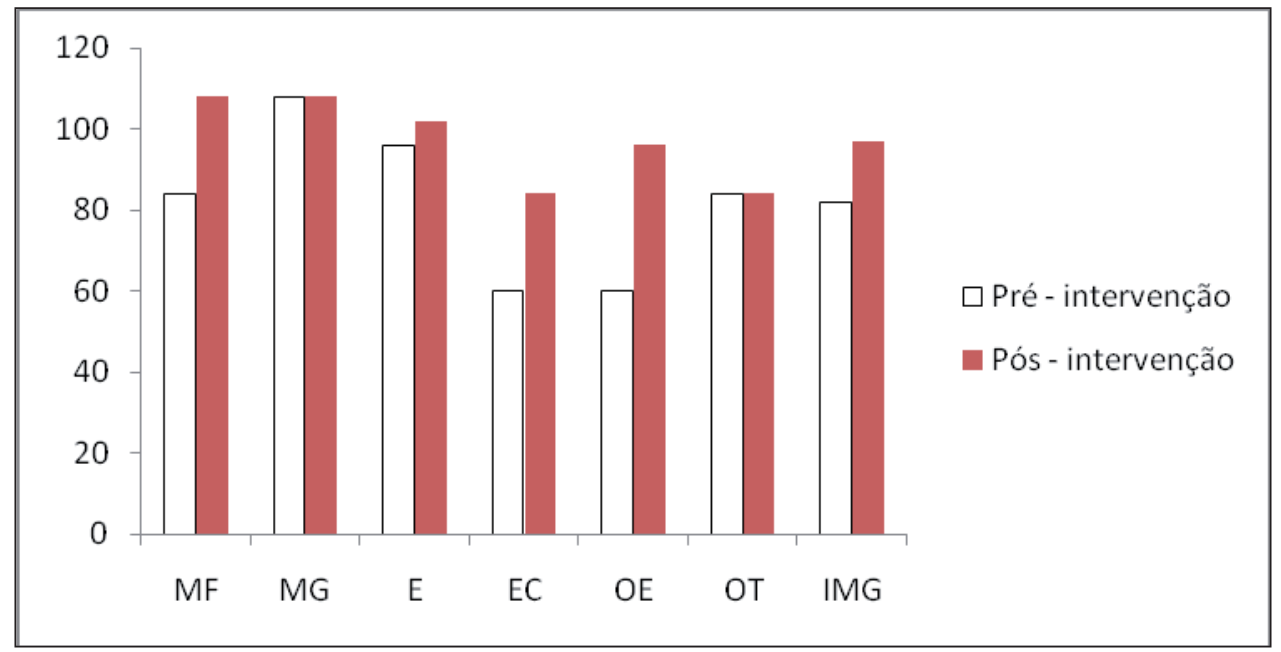

Figura 2: Gráfico do perfil motor do P1

Fonte: Barbosa (2013).

Com o decorrer do programa de equoterapia P1 foi adquirindo mais confiança, agilidade e mobilidade sobre o cavalo, o que oportunizou inúmeras vivências psicomotoras. Contudo o P1 já apresentava a motricidade global (MG) acima do esperado para a idade (nove anos) de modo que, é possível que o programa de equoterapia tenha refletido de forma mais efetiva no aprimoramento das aptidóes motoras com maior déficit antes da intervenção; além disso, com relação aos testes de organização temporal (OT), estes exigem mais concentração e atenção do que outros da escala, áreas as quais o praticante apresenta dificuldades, o que pode ter influenciado na manutenção do resultado.

$\mathrm{Na}$ escala de desenvolvimento esse participante avançou dois níveis, isto é, passou de "inferior" para "normal médio". Assim, ressalta-se que o P1 obteve melhora nas aptidóes motoras relacionadas à motricidade fina, equilíbrio, esquema corporal e organização espacial de modo a influenciar em ganhos na idade motora geral (IMG), visto que ao final do programa de equoterapia obteve um avanço de 12 meses na mesma. 
Ao analisar a figura 3, notamos que P2 apresentou melhora na motricidade global (MG) e organização espacial (OE), permanecendo com as mesmas medidas na motricidade fina $(\mathrm{MF})$, equilíbrio (E), esquema corporal (EC) e organização temporal (OT).

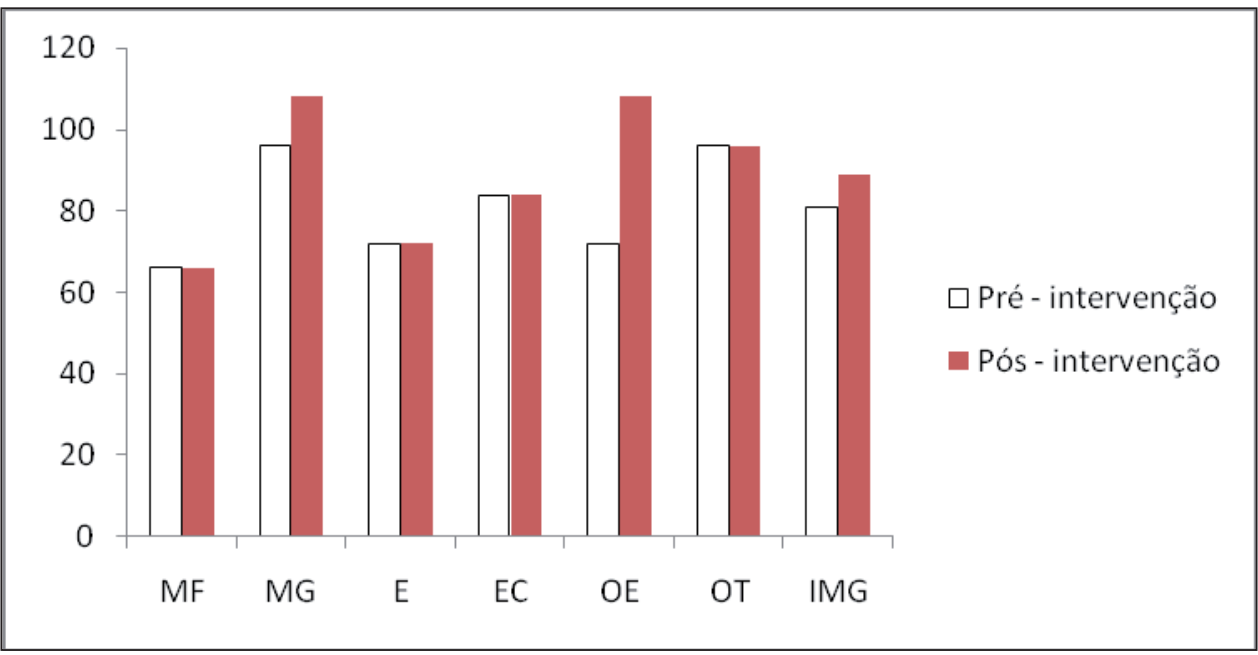

Figura 3: Gráfico do perfil motor do P2

Fonte: Barbosa (2013).

Durante a intervenção, P2 resistia a atividades que exigissem mudanças de postura / comando sobre o cavalo. A cada tentativa em que o cavalo não reagia de forma a obedecer aos comandos P2 tendia a esquivar-se da atividade; em uma das sessóes com o objetivo de conduzir o cavalo chegou a dizer que não iria conseguir e por isso não queria mais realizar a atividade, mas o mediador interviu e, a situação não se repetiu. P2 também apresentava dificuldade em localizar direita e esquerda em si própria.

$\mathrm{Na}$ escala de desenvolvimento esse participante permaneceu no mesmo nível denominado "normal médio", porém houve uma evolução em meses, mas não possibilitou a troca de nível. Assim, ressalta-se que a P2 obteve melhora nas aptidóes motoras relacionadas à motricidade global e a organização espacial de modo a influenciar em ganhos na idade motora geral (IMG), visto que ao final do programa de equoterapia obteve um avanço de cinco meses na mesma.

Ao analisar a figura 4, observamos que P3 apresentou melhora na motricidade fina $(\mathrm{MF})$, equilíbrio (E) e organização espacial $(\mathrm{OE})$ permaneceu com as mesmas medidas na motricidade global (MG), esquema corporal (EC) e organização temporal (OT). 


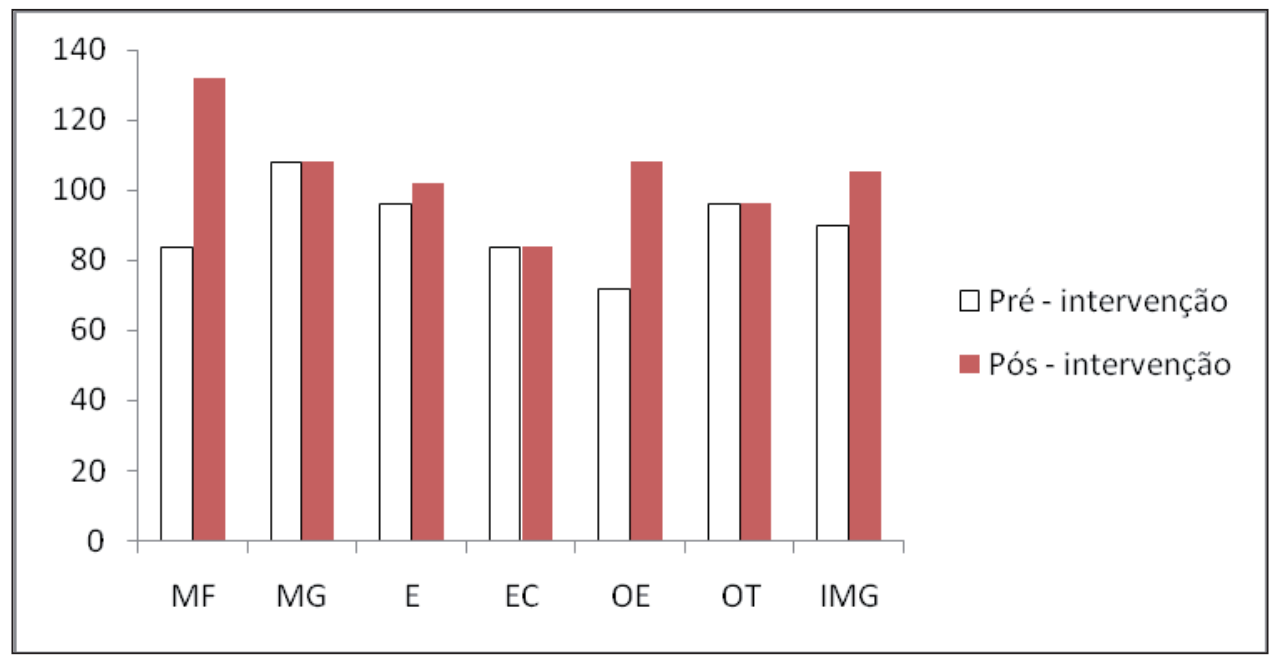

Figura 4: Gráfico do perfil motor do P3

Fonte: Barbosa (2013).

O P3 aceitava as atividades que exigiam maior esforço cognitivo sem esquivar-se, apresentava dificuldade em localizar direita e esquerda no próprio corpo e em mudanças de direção quando em montaria. Porém, não apresentou dificuldades para conduzir o cavalo em pequenos percursos e, demonstrou bastante domínio e vontade de atuar com o mesmo.

$\mathrm{Na}$ escala de desenvolvimento esse participante avançou um nível, isto é, passou de "inferior" para "normal baixo". Assim, ressalta-se que o P3 obteve melhora nas aptidóes motoras relacionadas à motricidade fina, equilíbrio e organização espacial de modo a influenciar em ganhos na idade motora geral (IMG), visto que ao final do programa de equoterapia obteve um avanço de 12 meses na mesma.

Ao analisar a figura 5, notamos que o $\mathrm{P} 4$ apresentou melhora na motricidade fina (MF), equilíbrio (E), esquema corporal (EC) e organização espacial (OE) e permaneceu com as mesmas medidas na motricidade global (MG) e organização temporal (OT). 


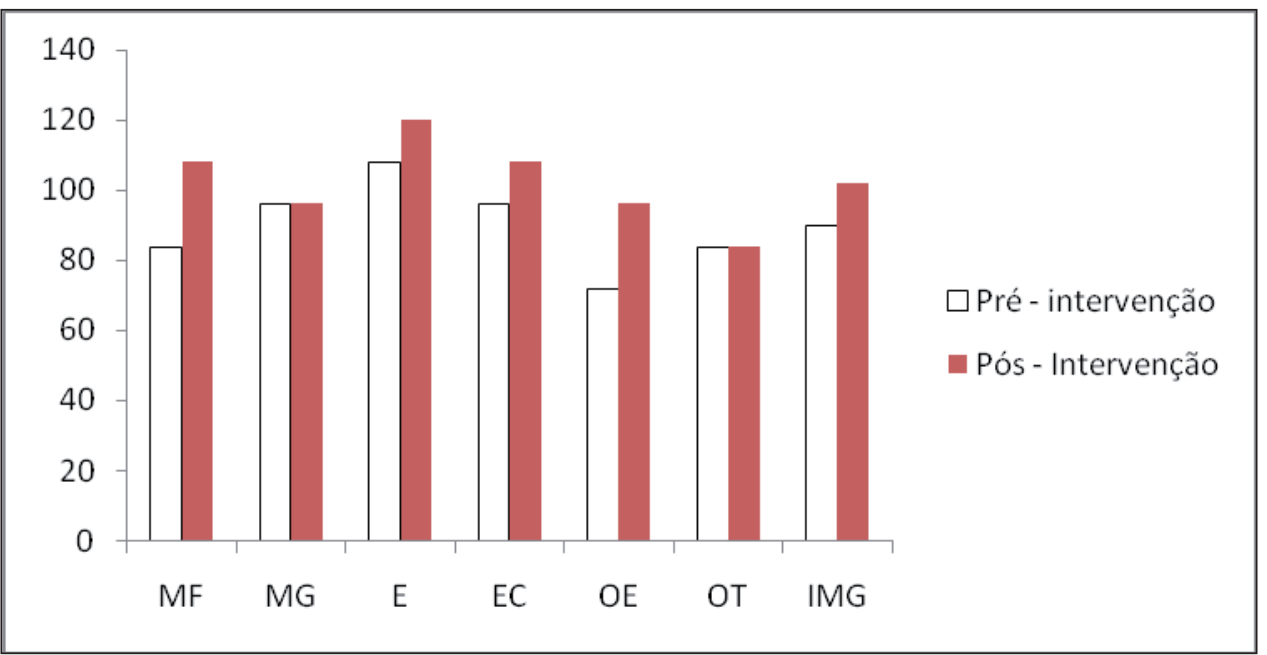

Figura 5: Gráfico do perfil motor do P4

Fonte: Barbosa (2013).

O P4 aceitava as atividades que exigissem maior esforço cognitivo sem reclamar, apresentava dificuldade em localizar direita e esquerda em seu próprio corpo e em mudanças de direçâo quando em montaria, manifestava alguma dificuldade para conduzir o cavalo em pequenos percursos, no entanto, demonstrava bastante domínio sobre ele e vontade de atuar com o mesmo.

$\mathrm{Na}$ escala de desenvolvimento esse praticante avançou um nível, isto é, passou de "normal baixo" para "normal médio". Assim, ressalta-se que o P4 obteve melhora nas aptidóes motoras relacionadas à motricidade fina, equilíbrio, esquema corporal e organizaçáo espacial de modo a influenciar em ganhos na idade motora geral (IMG), visto que ao final do programa de equoterapia obteve um avanço de nove meses na mesma.

Ao analisar a figura 6, notamos que o P5 apresentou melhora no equilíbrio (E) e organização temporal (OT), permaneceu com as mesmas medidas na motricidade fina (MF), motricidade global (MG) e esquema corporal (EC) e teve um pequeno decréscimo na organização espacial (OE). 


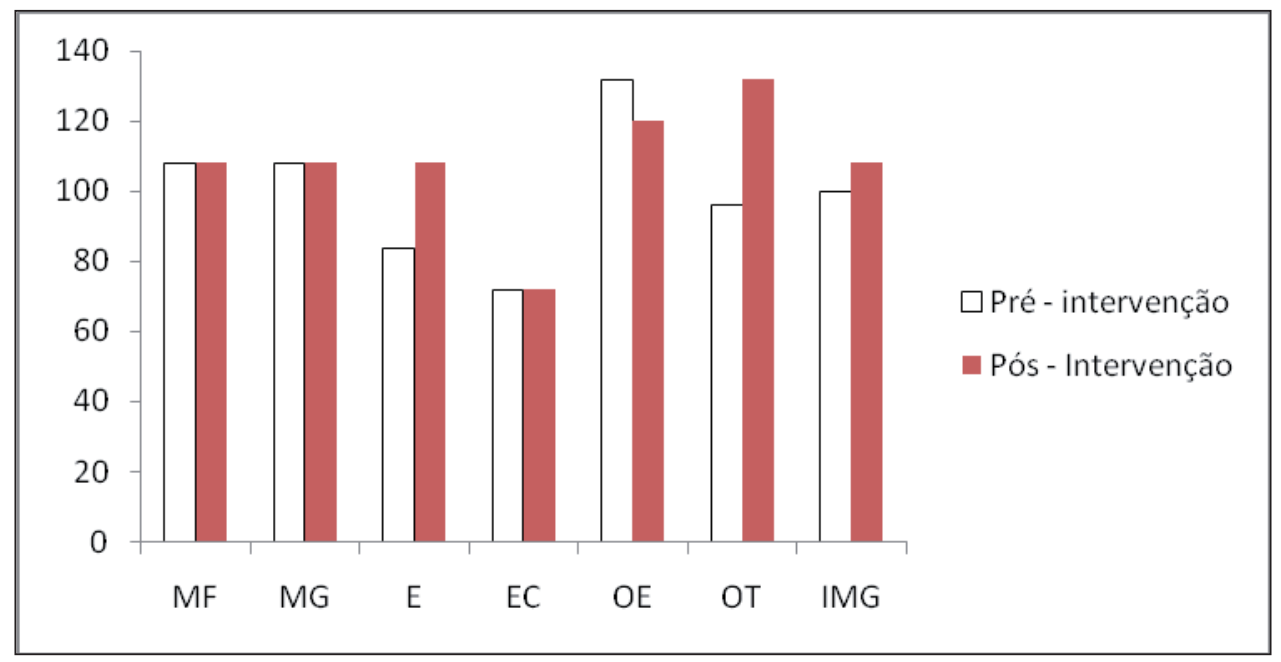

Figura 6: Gráfico do perfil motor do P5

Fonte: Barbosa (2013).

O P5 também aceitava as atividades que exigiam maior esforço cognitivo sem esquivar-se; no início do programa de equoterapia apresentava dificuldade em localizar direita e esquerda em seu próprio corpo. O mesmo se observou em mudanças de direçáo quando em montaria; manifestava alguma dificuldade para conduzir o cavalo em pequenos percursos, no entanto, demonstrava vontade de interagir com o mesmo.

$\mathrm{Na}$ escala de desenvolvimento esse praticante avançou um nível, isto é, passou de "normal alto" para "superior". Assim, ressalta-se que o P5 obteve melhora nas aptidóes motoras relacionadas a equilíbrio e organizaçáo temporal de modo a influenciar em ganhos na idade motora geral (IMG), visto que ao final do programa de equoterapia obteve um avanço de cinco meses na mesma.

Considerando a estruturaçáo e o desenvolvimento do programa de equoterapia esperava-se que as melhoras ocorressem em todas as habilidades motoras avaliadas, para todos os praticantes de equoterapia, no entanto, como apontado anteriormente, isso não foi observado.

Vilar (2010) abordou em seu estudo as relaçóes entre o cérebro e o comportamento e, apresentou que o mesmo é dividido em três unidades funcionais básicas, se houver desordens em uma dessas unidades pode haver diferentes alteraçóes no processo de aprendizagem. Caso ocorra na primeira unidade pode haver problemas de atenção, hipo ou hiperatividade, o que é observado em crianças com dificuldades de aprendizagem. Na segunda unidade, a interferência ocorre na natureza sequencial da análise, levando a desordens no processamento ou reconhecimento da informaçáo, podendo levar a omissáo ou distorção de dados. Quanto às desordens na terceira unidade podem causar alteraçóes na planificação das açôes e na resolução de problemas. Quanto a essas unidades, observam-se alteraçôes semelhantes àquelas apresentadas pelo TDAH, o que implica refletir quanto ao nível de conexões do sistema nervoso 
central e que alteraçôes no lobo frontal, como observado em pessoas com TDAH podem vir a ter influência em todo o funcionamento do córtex.

Estas três unidades apresentam uma organização interfuncional, que são à base de todas as atividades cognitivas e motoras do ser humano (VILAR, 2010). Assim, como aponta Vilar (2010) com relação ao aspecto motor, a terceira unidade é composta pela praxia global e a praxia fina, sendo esta relacionada à concentração, organização e especialização hemisférica para a realização de movimentos finos em tarefas de dissociação digital e de preensão construtiva com uma participação significativa da atenção e fixação visual, a especialização ocorre entre os seis e sete anos. Em nosso estudo, P2 e P5, ambos com sete anos de idade, apresentaram maior média comparado aos demais quanto a hiperatividade/impulsividade no SNAP-IV, respectivamente (8,5 e 8), não apresentaram alterações do pré para o pós-teste quanto a motricidade fina, isso pode ter ocorrido devido ao maior índice relacionado a hiperatividade/impulsividade o que gera maior dificuldade de atenção e concentração, visto que, segundo Vilar (2010), é necessário significativa atenção e fixação visual para o desenvolvimento dessa praxia. E, ainda, por estarem na fase de especificação da habilidade, sete anos, o tempo de intervenção em equoterapia (três meses) pode não ter sido suficiente para gerar mudanças significativas nesses dois praticantes quanto à motricidade fina.

Com relação ao equilíbrio, somente P2 não apresentou ganhos quando avaliado com a EDM, o resultado desse dado merece uma reflexão, pois em todos os estudos relatados na literatura são indiscutíveis os benefícios oferecidos pela equoterapia quanto a ganhos no equilíbrio; pois conforme afirma Copetti, Graup e Lopes (2006), nesse tipo de intervenção ocorre repetida solicitação do sistema vestibular, o que estimula conexôes entre os canais semicirculares, onde os otólitos (células ciliares) atraem as oscilaçóes de endolinfa, devido aos movimentos da cabeça.

A noção dos segmentos corporais no espaço e a reeducação dos mecanismos reflexos são provocados devido à repetição do movimento. Selvinen (2006) define equilíbrio como a capacidade de manter um centro de massa sobre uma base de suporte, o que ocorre devido a uma associação complexa que abrange a recepção e integração de estímulos sensoriais, planejamento motor, atenção e execução muscular, assim danos em uma dessas áreas pode afetar o equilíbrio. A literatura traz que o TDAH é um distúrbio neurobiológico que pode alterar as funções executivas desempenhadas pelo lobo frontal. As características assinaladas no SNAP-IV pelos pais e professores, apesar de todas as crianças serem classificadas como hiperativas/impulsivas, P2 foi o participante que apresentou maior média $(8,5)$, em comparação aos outros participantes, em relação à hiperatividade/impulsividade. Segundo Selvinen (2006) a dificuldade na capacidade de concentração e atenção pode interferir na qualidade do desempenho relacionado ao equilíbrio. Coincidentemente P2 é a única praticante do sexo feminino, todavia não foi possível encontrar na literatura convergências entre gênero e equilíbrio para a idade estudada que permitissem estabelecer alguma relação, como também qualquer outra inferência que pudesse justificar por que em P2 não foram observados ganhos nesses aspectos.

Com relação à organização espacial, esta resulta da noção de espaço, adquirida pela interpretação das informaçôes sensoriais e pela construção de conceitos espaciais em termos sensoriais e motores. Esta envolve a integração de dados visuais e tátil-cinestésica, que 
permitem perceber a posição do corpo no espaço (VILAR, 2010). Copetti, Graup e Lopes (2006) acrescentam que a formação de esquemas motores novos é favorecida pela prática equoterápica, o estudo das atitudes e da postura permite compreender facilmente esse modelo, visto que a posição de cada um dos membros ou segmentos fica bem delimitada de acordo com três dimensóes do espaço, o que vem ao encontro do movimento tridimensional do cavalo. Observa-se em nosso estudo que $80 \%$ dos praticantes obtiveram ganhos quanto a organização espacial, P5 foi o único que apresentou diminuição, no entanto, este apresentou pontuação máxima no pré-teste, pontuando quatro anos acima da sua idade cronológica; assim, mesmo com a diminuição continuou exponencialmente acima da média esperada. Um fato que chamou a atenção foi que, no dia do pós-teste P5 não conseguiu focar a atenção nas instruções para esse teste em específico e, assim não pontuou no último item, por isso ficou um nível abaixo do que observado no pré-teste, P5 pontuou esse item muito acima da idade cronológica, o que é difícil manter, no entanto, a pequena diminuição não afetou no resultado geral.

Quanto à motricidade global, esquema corporal e organização temporal, observa-se que os ganhos ocorreram em um número mínimo de participantes (1:5 motricidade global, 2:5 esquema corporal e 1:5 organização temporal). Na tentativa de averiguar a possibilidade de convergência com os dados disponíveis na literatura que respaldassem os resultados, os dados foram cruzados com achados literários referentes ao desenvolvimento motor, habilidade motora, aptidão motora, características do TDAH, psicomotricidade, desenvolvimento do programa e os testes aplicados, no entanto, nenhuma convergência pôde ser diretamente estabelecida, assim infere-se que tal correspondência não pôde ser averiguada, pois o período de intervenção durou apenas três meses, ou seja, é possível que com maior tempo de prática haja outro direcionamento quanto à confluência dos resultados encontrados e os dados da literatura.

Ainda, apesar de todos os praticantes terem atingido as metas propostas no decorrer do programa de equoterapia, pois todos evoluíram na escala de desenvolvimento motor (EDM), há as diferenças individuais que acompanham todo o processo de aprendizado, pois apesar de haver uma sequencia quanto à progressão do desenvolvimento psicomotor também existe um ritmo de aprendizado, que pode ser influenciado por aspectos genéticos e/ou ambientais; e que devido a possíveis alteraçóes no processamento de informação, e a presença do transtorno, é possível que os praticantes não tenham desenvolvido estratégias de movimento adequadas para realizar todas as tarefas solicitadas pela EDM, associado também às inadequaçóes quanto à atenção e concentração, o que, por exemplo, era necessário para o teste de organização temporal. Assim, acredita-se que trabalhos posteriores com um número maior de participantes com indicativos de TDAH e também com tempo maior de intervenção equoterapêutica possam vir a preencher essa lacuna.

\section{Conclusāo}

Com relação ao efeito do programa de educação/reeducação de equoterapia sobre o desenvolvimento psicomotor de crianças com transtorno de déficit de atenção e hiperatividade (TDAH), pode-se inferir que de forma geral o programa de equoterapia foi adequado para o desenvolvimento psicomotor dos praticantes do estudo, visto que todos evoluíram quanto à 
idade motora geral (IMG) e os ganhos foram estatisticamente significantes. Quanto à evolução psicomotora observamos que todas as crianças evoluíram com a intervenção, visto que todos obtiveram um aumento médio de 8,6 meses em idade cronológica.

A equoterapia promove efeitos multifatoriais, favorecendo respostas adaptativas, promovendo benefícios psicomotores aos praticantes por meio da integração de estímulos aferentes e eferentes.

Mediante o que foi apresentado, foi possível inferir que a equoterapia consiste em uma intervenção que reúne inúmeros estímulos com ferramentas capazes de influenciar com sucesso diferentes aspectos, por meio da interação com o cavalo, a movimentação tridimensional e o contato com a natureza.

Assim, considera-se que esse estudo contribuiu com informações que possam vir a facilitar e tornar mais adequado o direcionamento de açóes, por meio dos profissionais da área da saúde e educação, possibilitando um ambiente equoterapêutico mais favorável à promoção da aprendizagem e independência das crianças com indicativos do TDAH.

\section{REFERÊNCIAS}

BARBOSA, G. O. Efeito de um programa de equoterapia nos aspectos psicomotores de crianças com indicativos do TDAH. 2013. 191f. Dissertação (Mestrado em Educação Especial) - Centro de Educação e Ciências Humanas, Universidade Federal de São Carlos, São Carlos, 2013.

COPETTI, F. et al. Comportamento angular do andar de crianças com Síndrome de Down após intervenção com equoterapia. Revista Brasileira de Fisioterapia, São Carlos, v. 11, n. 6, p. 503-507, 2007.

COPETTI, F.; GRAUP, S.; LOPES, L. F. D. O efeito de atividades psicomotoras com e sem o uso do cavalo em crianças com Síndrome de Down. In: CONGRESSO BRASILEIRO DE EQUOTERAPIA, 12., 2006, Brasília. Anais eletrônicos... Brasília: ANDE-BRASIL, 2006. p. 413-421. Disponível em: < http://www.ncpg-kenniscentrum.nl/documenten/twaalfdeintcongresfrdi.pdf>. Acesso em: 22 jan. 2FALCÃO, H. T.; BARRETO, M. A. M. Breve Histórico da psicomotricidade. Revista Eletrônica do Mestrado Profissional em Ensino de Ciências da Saúde e do Ambiente, São Paulo, v.2, n.2, p. 84-96, 2009. Disponível em: < http://www.cienciamao.usp.br/tudo/exibir.php?midia=@midias\&cod=_ rempec $>$. Acesso em: 23 jan. 2013.

FRANK, A.; MCCLOSKEY, S.; DOLE, R. L. Effect of hippotherapy on perceived self-competence and participation in a child with cerebral palsy. Pediatric Physical Therapy, Canidian, v.3, n.23, p. 301308, 2011.

FREIRE, H.B.G. Equoterapia - teoria e técnica: uma experiência com crianças autistas. São Paulo: Vetor, 2000.

GRAUP, S. et al. O efeito da equoterapia sobre o padrão motor da marcha em crianças com Síndrome de Down: uma análise biomecânica. EFDeportes, Buenos Aires, ano 11, n. 96, 2006. Disponível em:<http://www.efdeportes.com/>. Acesso em: 15 jun. 2011.

LE BOUCH, J. Educação psicomotora. 2. ed. Porto Alegre: Artes Médicas, 1987.

MARCONI, M.A.; LAKATOS, E.M. Técnicas de pesquisa. São Paulo: Atlas, 1990. 
MARINS, B.B. O cavalo como instrumento psicomotor. 2010. Disponível em: <http://equitacaoespecial. blogspot.com/2010/09/psicomotricidade-e-equoterapia-o-corpo.html>. Acesso em: 23 maio 2011.

MEDEIROS, M.; DIAS, E. Equoterapia: bases e fundamentos. Rio de Janeiro: Revinter, 2002.

MEREGILlanO, G. Hippotherapy. Physical Medicine and Rehabilitation Clinics of North America, v.4, n. 15, p. 843-854, 2004.

MURPHY, D.; KAHN-D’ANGELO, L.; GLEASON, J. The effect of hippotherapy on functional outcomes for children with disabilities: a pilot study. Pediatric Physical Therapy, Canidian, v.3, n. 20, 264-270, 2008.

NEGRI, A. P. et al. Influência da equoterapia no equilíbrio de uma praticante com síndrome de Mórquio: estudo de caso. In: CONGRESSO BRASILEIRO DE EQUOTERAPIA, 4.; CONGRESSO LATINO-AMERICANO DE EQUOTERAPIA, 1., 2008, Curitiba. Anais... Curitiba: ANDEBRASIL, 2008. p. $194-199$.

PEREIRA, H. S.; ARAÚJO, A. P. Q.; MATTOS, P. Transtorno do déficit de atenção e hiperatividade (TDAH): aspectos relacionados à comorbidade com distúrbios da atividade motora. Revista Brasileira de Saúde Materno Infantil, Recife, v.5, n.4, p. 391-402, 2005.

PLISKA, S. R.; CARLSON, C. L.; SWANSON, J. M. ADHD with comorbid disorders: clinical assessment and management. New York: Guilford Press, 2001.

POETA, L.S; ROSA-NETO, F. Intervenção motora em uma criança com transtorno de déficit de atenção/hiperatividade TDAH. EFDeportes, Buenos Aires, n. 89, 2005. Disponível em: < http://www. efdeportes.com/>. Acesso em: 19 maio 2011.

ROHDE, L.; HALPERN, R. Transtorno de déficit de atenção/hiperatividade: Atualização. Jornal de Pediatria, Rio de Janeiro, v.80, n.2, p.61-70, 2004.

ROSA-NETO, F. Manual de Avaliação Motora. Porto Alegre: Artmed, 2002.

SELVINEN, S. Equoterapia e a integração multissensorial do equilíbrio e da postura. In:

CONGRESSO BRASILEIRO DE EQUOTERAPIA, 12., 2006, Brasília. Anais eletrônicos...

Brasília: ANDE-BRASIL, 2006. p. 268-270. Disponível em: < http://www.ncpg-kenniscentrum.nl/ documenten/twaalfdeintcongresfrdi.pdf>. Acesso em: 22 maio 2013.

STERBA, J. A. et al. Horseback riding in children with cerebral palsy: effect on gross motor function. Developmental Medicine and Child Neurology, v. 5, n. 44, p. 301-308, 2002.

VILAR, C. E. C. Dificuldades de aprendizagem e psicomotricidade: estudo comparativo e correlativo das competências de aprendizagem acadêmicas e de factores psicomotores de alunos do $2^{\circ}$ e $4^{\circ}$ ano do ensino básico, com e sem dificuldades de aprendizagem. 2010. 69 f. Dissertação (Mestrado em reabilitação psicomotora) - Faculdade de Motricidade Humana, Universidade Técnica de Lisboa, Lisboa, 2010.

Recebido em: 29/04/2013

Reformulado em: 10/01/2014

Aprovado em: 10/02/2014 